\title{
The Capability Improvement Strategy of Cross-border E-commerce Supply Chain Service Providers
}

\section{Yi Xu*}

Zhejiang Wanli University, Ningbo 315100, Zhejiang Province, China. E-mail: 759755773@qq.com

Abstract: In the development process of cross-border e-commerce, cross-border e-commerce supply chain providers play an essential role. Within their business scope, they are not good at cross-border logistics, overseas warehouses, information security in supply chain and other aspects. With the support of national policies, it is possible to innovate cross-border logistics service mode, improve the development ability of overseas warehouses, establish information supply chain partnership, attract or strengthen the training of cross-border e-commerce talents, so as to improve the ability.

Keywords: Cross-border E-commerce; Cross-border E-commerce Supply Chain Service Providers; Ability to Ascend

Under the influence of globalization, today's international trade is full of opportunities and challenges. In the face of the complex and volatile economic situation, cross-border e-commerce, as a new type of trade, is difficult for the general supply chain to meet the development needs of some projects, so the requirements for cross-border e-commerce supply chain are more stringent. Therefore, in order to improve the competitiveness of enterprises and realize sustainable development, the competition of cross-border e-commerce enterprises will be transformed into the competition of supply chain management, and more attention will be paid to supply chain management ${ }^{[1]}$ and the ability level of enterprise supply chain service providers. At present, logistics, information and other business levels are not perfect, even if some countries put forward the "One Belt and One Road" policy and the guidance on actively promoting supply chain innovation and application issued by the general office of the state council, they provide supply chain services from different aspects to help promote the development of China's supply chain. However, in the face of various national encouragement policies, suppliers of cross-border e-commerce supply chain still need to improve their own capabilities through themselves, keep their advantages and continue to extend them, and improve their capabilities in combination with the weak support policies of the country.

\section{Cross-border e-commerce supply chain service provider}

Cross-border e-commerce supply chain management is the core of information flow, logistics and cash flow, and its own internal management already has a certain complexity and dynamic, the external factors in many aspects because of supply chain management and international policy, will bring burden to cross-border e-commerce platform, so by choice for outsourcing to reduce the burden of cooperation, to help platform to enhance competitiveness. One of cross-border e-commerce supply chain service providers are entrusted outsourcing, revolves around cross-border e-commerce platform main business customs clearance, warehousing (overseas warehouse, bonded warehouse, etc.). Cross-border logistics services as a platform to retain customers, give full play to their own advantage, and increase the

This is an open-access article distributed under the terms of the Creative Commons Attribution Non-Commercial License (http://creativecommons.org/licenses/by-nc/4.0/), which permits unrestricted non-commercial use, distribution, and reproduction in any medium, provided the original work is properly cited. 
volume. The platform can focus on the strengths, to their own interests to maximize, and profitable for both sides.

\section{Problems existing in the capability of service providers in cross-border e-commerce supply chain}

\subsection{Problems existing in cross-border logistics}

\subsubsection{Cross-border logistics has high cost and long cycle}

The transportation, storage, management and other aspects of goods in the cross-border process are much more complicated than those within China, so the cost is correspondingly much higher than that within China ${ }^{[2]}$. Although the service providers will control the cost, there will still be some uncontrollable factors, such as customs tariffs, which cannot control its fluctuation. Cross-border logistics that spans from domestic to overseas, has a large space span, and also needs to face policies of different countries and regions. The process is complicated and consumes a long time, so the logistics delivery cycle is long.

\subsubsection{Cross-border logistics order information is not transparent enough}

Cross-border logistics itself takes a long time and involves many intermediate processes. Once it is delayed, many logistics companies cannot update the data timely. The low level of logistics service providers will also lead to the inability of customers to get the latest status of their packages.

\subsubsection{Missing and damaged parts in cross-border logistics}

Cross-border electricity is to trade between two or more than two countries. Plus logistics delivery cycle long, abd express packages often hitches in transportation logistics company turnover. Once the hand of the parcel appear lost or damaged, it is difficult to determine the responsibility, and finally the logistics companies can only take a loss by itself.

\subsubsection{Return and replacement of cross-border logistics}

Whether the customer wants to return or replace the goods due to their own reasons, or goods' or other reasons, the customer needs to contact the logistics company to send the goods back, and the expenses incurred during the period and all the problems need to be borne by the customer himself. In the return process, a series of customs clearance have to be gone through, general inspection and other processes, and finally the logistics cost higher than the commodity value can be made. If the company has to bear the result, it is absolutely unacceptable.

\subsection{Problems existing in overseas warehouses}

\subsubsection{The establishment and operation costs of overseas warehouses are high}

First of all, the cost of establishing an overseas warehouse is quite high, which requires a large amount of capital to prepare the equipment and information system needed. Second, there is a need for human resources, and foreign human capital is high, leading to high costs.

\subsubsection{Overseas warehouses expansion competition}

Under the globalization situation, multilateral trade need to obtain more profits. In the face of international postal and international express delivery, under the oppression of the global warehouse become a target for most of the large service providers, it is important to get more customers and maintain the relationship in order to get more profit, so no one will dominate the field of overseas warehouse, which can avoid the expansion of fierce competition.

\subsubsection{Image problems of overseas warehouses}

Due to the differences of culture, policy and so on among countries, China for overseas laws and regulations of the construction of the warehouse is not yet perfect. Because some illegal cross-border electricity business enterprises are opportunistic and the present situation of tax evasion is frequent, the serious influence to the international image of China's overseas warehouse ${ }^{[3]}$ and economic order, cause China's enterprise overseas warehouse constructions in some 
countries and regions, are restricted by a series of measures.

\subsection{Information security in the supply chain}

In the process of transaction, the service supply chain needs to share information. However, in cross-border transaction, information goes from one party to another, so some basic information of customers is at risk of being stolen. Moreover, the Internet itself has security risks. Once the information system is attacked, information exchange is not timely and information acquisition is inaccurate, which brings risks to the operation of the supply chain ${ }^{[4]}$ to a certain extent, as well as the job-hopping of supply chain employees. If the internal information of the enterprise is taken away, it will bring incalculable consequences to the enterprise.

\subsection{Shortage of high-end talents in cross-border e-commerce supply chain}

The rapid development of cross-border e-commerce has caused a large shortage of cross-border e-commerce talents, and its complex trade forms have led to the difference between cross-border e-commerce supply chain and ordinary supply chain. Because of the international trading involved, so it is necessary to have rich theoretical knowledge of supply chain and logistics, customs, national culture, excellent foreign language communication ability and so on.In spite of the positive response to the development needs of colleges and universities, courses in cross-border electricity, cultivate a lot of students. But due to lack of experience, operational capability is not strong, the enterprise training can be competent for jobs is still needed. At the same time, the ability of the operation personnel of overseas warehouses is also extremely high, because overseas warehouses also need to provide local customers with product introduction, after-sales services, etc., so the operation personnel of overseas warehouses also need to be compound high-end talents, but also lack.

\section{Capability improvement strategy of cross-border e-commerce supply chain}

\subsection{Innovation of cross-border logistics service model}

All the way in the "area", under the action of the increasing trade, cross-border logistics development is full of opportunities, to the warehousing information intelligent push the logistics mode, initiative and the coordinated development of cross-border e-commerce, electronic business development trend of demand for cross-border mobile logistics service, also can strengthen the cooperation with local logistics company, the information transparency, realize logistics localization, as much as possible to shorten the cycle and in the distribution of all kinds of problems.

\subsection{Improve the development ability of overseas warehouses}

\subsubsection{Choose an overseas warehouses mode suitable for its own development}

When their own funds are sufficient, they can choose to build warehouses overseas and upgrade and transform them according to their actual strength. At the same time, they can also subsidize other enterprises. When funds are insufficient, their business needs and not hours, We can choose the form of co-construction or leasing. When their own conditions and strength slightly less, can choose to use overseas warehouse, reduce unnecessary consumption.

\subsubsection{Establish the image of overseas warehouses}

With the development of overseas warehouses, the ability level is not uniform, even so, competition is everywhere. Enterprises may, from the perspective of the enhanced cross-border logistics information infrastructure, build authoritative information tracking platform at home and abroad, timely grasp the overseas warehouse inventory information and logistic progress, and realize high synergy of domestic enterprises and cross-border overseas warehouse operations management. It is important to improve the logistics speed and provide consumers with efficient cross-border logistics services ${ }^{[4]}$. It is important to accurate market demand, improve supply allocation, avoid unnecessary stockpiling, actively promote the coordinated development of cross-border logistics and cross-border 
e-commerce, and establish overseas warehouse brand through continuous innovation.

\subsubsection{Establish and improve overseas warehouses management system}

Enterprises should have image awareness, strengthen communication between employees and partners, and regularly hold system revision meetings. It is not only to improve their self-discipline ability, but also to continuously enhance their credibility.

\subsection{Establish of information supply chain partnership}

It is necessary to look for professional Internet companies as the partners and invite third-party payment institutions to jointly create an information payment system that meets the needs, so as to ensure information security and payment security and be responsible to the society and consumers. At the same time, but also to strengthen the confidentiality of internal staff task. And the leaker must be strict punished, and internal and external must be repaired to improve the ability..

\subsection{Attract or strengthen the training of cross-border e-commerce talents}

According to the needs of talents, enterprises take the initiative to offer olive branches to outstanding talents and attract them, so as to improve their own strength. The company selects outstanding talents through internal training, and then carries on further study, and develops talents that meet its own development needs.

At present, colleges and universities are responding to the development demand and making efforts to cultivate talents in this field. However, the theoretical knowledge in textbooks is still limited. Enterprises can cooperate with colleges and universities to offer internship opportunities, provide students with practical opportunities, accumulate experience and find talents they need at the same time.

\section{Conclusion}

Cross-border e-commerce supply chain service provider is a cross-border derivatives of electricity supply chain, in the face of complicated international trade form, which makes the service providers need to constantly improve cross-border logistics services, overseas warehouse service, transaction service and perfect information system, etc. In order to raise the ability level, it is necessary to seize the talent at the same time, constantly promote in the future development and to provide better quality and service.

\section{References}

1. He J. Cross-border e-commerce supply chain model innovation: Attribute feature relationship model and its prerequisites (in Chinese). China Business and Market 2017; 31(3): 52-61.

2. Liu M. Research on problems and strategies in the development of cross-border e-commerce logistics in China (in Chinese). Commercial Economy 2016; (11): 75-76. doi: 10.3969/j.issn.1009-6043.2016.11.030.

3. Zheng Y, Chen D, Sun Y, et al. Research on the problems and countermeasures in the development of cross-border e-commerce warehouses in China (in Chinese). Commercial Economy 2019; (1): 80-81. doi: 10.3969/j.issn.1009-6043.2019.01.031.

4. Guo X, Liu X. Risk analysis of cross-border e-commerce service supply chain (in Chinese). Enterprise Technology and Development 2014; (16): 7-9. doi: 10.3969/j.issn.1674-0688.2014.16.003 